Agrotrópica 32(3): 197 - 206. 2020.

Centro de Pesquisas do Cacau, Ilhéus, Bahia, Brasil

\title{
DESEMPENHO ECONÔMICO-FINANCEIRO DE SISTEMA AGROFLORESTAL NA REGIÃO DE TOMÉ AÇU, PARÁ
}

\author{
Jair Carvalho dos Santos ${ }^{1}$, Rafael Moysés Alves ${ }^{1}$, Saulo Fabrício da Silva Chaves ${ }^{2}$ \\ ${ }^{1}$ Embrapa Amazônia Oriental, Trav. Dr. Enéas Pinheiro, s/nº, Bairro Marco, 66095-903, Caixa postal 48, Belém, PA. \\ jair.santos@embrapa.br; rafael-moyses.alves@embrapa.br. \\ ${ }^{2}$ Universidade Federal de Viçosa, Av. Peter Henry Rolfs, s/n, Campus Universitário, 36570-900, Viçosa, MG. \\ saulofabricioagro@gmail.com.
}

\begin{abstract}
Os sistemas agroflorestais (SAF) são considerados alternativas de modelos adequados para ocupação produtiva de solos de regiões tropicais. Diversos modelos de combinação de cultivos têm sido idealizados por instituições de pesquisas e produtores rurais, e estudados agronomicamente. No entanto, poucos estudos têm objetivado avaliar o desempenho econômico desses modelos. Este estudo objetivou estimar o custo de produção e a rentabilidade de um sistema agroflorestal, nas condições agroclimáticas do município de Tomé Açu/PA. O método utilizado foi a análise de benefício-custo e os indicadores de viabilidade foram: valor presente líquido, relação benefício-custo, taxa interna de retorno, payback econômico e custo unitário de produção. Os resultados obtidos demonstram que o modelo de sistema agroflorestal avaliado apresenta viabilidade econômico-financeira com boa margem de segurança, o que o caracteriza como uma boa opção de investimento por parte dos agricultores da região. Os componentes culturais bananeira, cupuaçuzeiro, pimenteira do reino e taperebazeiro também apresentaram desempenho econômico positivo no sistema, colaborando para a viabilidade do SAF. No entanto, o componente arroz apresentou desempenho econômico negativo, o que indica que deve passar por ajustes no seu processo produtivo, tecnológico ou de gestão. Em ciclos de preços baixos, a pimenta do reino também apresentou rentabilidade negativa.
\end{abstract}

Palavras-chave: análise econômica, SAF, consórcio.

\section{Economic and financial perfomance of agroforestry system in Tomé Açu region,}

Pará. The agroforestry systems are considered alternatives of adequate models for productive occupation to tropical regions soils. Several cultivation combination models have been idealized by research institution and farmers, agronomically studied. However, few studies have the objective of evaluate these models economic performance. This study had the objective of estimate production cost and profitability of an agroforestry system, in the agroclimatic condition of Tome Açu/PA. The method used was the benefit-cost analysis and the indicators was: net present value, benefit cost ratio, internal rate of return, payback period and unit cost of production. The results obtained demonstrate that the agroforestry system model evaluated presents economic and financial viability with a good safety margin, which characterizes it as a good investment option by farmers in the region. The banana tree, cupuassu tree, black pepper and yellow mombin cultural components also showed positive economic performance in the system, contributing to the viability of the SAF. However, the rice component showed a negative economic performance, which indicates that it must undergo adjustments in its productive, technological or management process. In low price cycles in the studied period, black pepper also showed negative profitability.

Key words: economic analysis, AFS, consortium. 


\section{Introdução}

Os sistemas agroflorestais (SAF) são considerados, a priori, alternativas de modelos adequados para ocupação produtiva de solos de regiões tropicais, especialmente na região amazônica. Representam combinações de espécies agrícolas e florestais, de diferentes ciclos de vida e de porte, e cultivados de forma simultâneas e/ou sequenciais (Paludo e Costabeber, 2012).

Os SAF apresentam diversas características positivas, entre as quais, favorecem a eficiência no uso do solo, na medida em que elevam o rendimento produtivo por unidade de área, por aproveitar melhor o espaço físico do solo, os nutrientes, a água e a luminosidade solar disponíveis. Em regiões onde há pouca disponibilidade de terra, essas particularidades tornam-se relevantes. No caso do Brasil, o crescimento populacional dos últimos anos, a expansão da fronteira agrícola e as modificações recentes no Código Florestal, têm reduzido cada vez mais a oferta relativa de terra disponível para a produção agropecuária e silvicultural. A possibilidade de usar o sistema para compor Áreas de Preservação Permanente e Reservas Legais tornao uma opção factível aos produtores (Silva, 2013) A diversificação produtiva, outra característica dos SAF, tende a reduzir os riscos econômicos do investimento (Varela e Santana, 2009). Esta diversificação proporciona, ainda, retorno econômico-financeiro escalonado por todo o período de cultivo, além de contribuir para a segurança alimentar do próprio produtor (Armengot et al., 2016; Cerda et al., 2014).

Por outro lado, a configuração inadequada dos componentes dos SAF, situação muito comum no meio produtivo, resulta em maior competição entre os componentes pelos fatores de crescimento e produção, o que configura uma desvantagem, aliado a maior dificuldade de gestão agronômica e administrativa por parte do produtor, devido ao aumento da necessidade de conhecimento agronômico e comercial de um maior número de culturas e produtos. Esses fatores, analogamente, constituem aumento nos riscos bioeconômicos do investimento (Henkel e Amaral, 2008).

O município de Tomé Açu, no estado do Pará, representa um dos principais polos de surgimento e exploração econômica de sistemas agroflorestais da região Amazônica, por iniciativa da ação de produtores rurais, especialmente de origem japonesa, que parecem ter uma maior propensão a experimentação de novos modelos de sistemas produtivos, e pela capacidade diferenciada de gestão de recursos agroeconômicos (Barros et al., 2009).

A iniciativa de gerar novos modelos de combinação de cultivos na forma de SAF tem sido realizada por instituições de pesquisa, universidades, entre outras, assim como por parte de produtores rurais. A Empresa Brasileira de Pesquisa Agropecuária-EMBRAPA, em seus centros de pesquisas na Amazônia brasileira, tem combinado espécies vegetais nativas da Região com espécies introduzidas, em modelos experimentais, que caracterizam SAF (Alves et al., 2018).

No entanto, poucos estudos têm objetivado avaliar o desempenho econômico desses modelos, muitas vezes, pelo estádio inicial de desenvolvimento dos componentes dos SAF, o que não oferece segurança para as análises, ou por não haver disponibilidade de dados sobre custos de produção ao longo do cultivo. Alguns trabalhos demonstraram o desempenho positivo dos SAF, como foi o caso de Santos (1996) e Araújo et al. (2015). No entanto, a pequena quantidade de resultados disponíveis demonstra que a sustentabilidade econômica de SAF ainda constitui uma hipótese a ser consolidada, até que uma quantidade significativa de estudos venha convergir para desempenhos positivos. Portanto, avaliar parâmetros econômicos subsidiados pelas informações desses componentes, em ambiente de SAF, seria estratégico para propiciar tomada de decisões pelo agricultor e pelos agentes creditícios.

Este trabalho objetivou estimar o custo de produção e a rentabilidade de um sistema agroflorestal, tendo cupuaçuzeiro (Theobroma grandiflorum (Willd. ex. Spreng) Schum.), taperebazeiro (Spondias mombin L.), bananeira (Musa spp.), pimenteira do reino (Piper nigrum L.), arroz (Oriza spp.) e feijão guandu (Cajanus cajan L. Millsp.), como componentes culturais, nas condições agroclimáticas do município de Tomé Açu/PA.

\section{Material e Métodos}

Região de Estudo - Caracteres edafoclimáticos

As condições edafoclimáticas e socioeconômicas que condicionam o desempenho agronômico do sistema produtivo avaliado são encontradas no município de 
Tomé Açu, que faz parte da microrregião de mesmo nome e da mesorregião Nordeste Paraense, estado do Pará, fazendo parte da Amazônia Oriental Brasileira. Nessa região, predomina o solo tipo Latossolo Amarelo, de textura média e de baixa fertilidade natural. O clima prevalecente é do tipo Ami, na classificação de Köppen, quente e úmido, com elevada precipitação pluviométrica e irregularmente distribuída durante o ano, o que pode resultar, normalmente, em deficiência hídrica no segundo semestre, período menos chuvoso do ano (Bolfe e Batistella, 2011).

Modelo de SAF - Características e Pressupostos

A escolha do sistema analisado foi feita com base na adoção por produtores da região de estudo e na disponibilidade de dados e informações básicas e complementares, em meio a grande diversidade de SAF. O modelo adotado na Fazenda Konagano e em outras fazendas atendeu a esses critérios. A identificação e a quantificação das variáveis componentes da avaliação do sistema foram feitas predominantemente com base nos resultados obtidos na Fazenda Konagano, onde o SAF já em fase avançada de produção, e complementadas com de outras fazendas (produtores) que adotam sistemas semelhantes e com resultados de diversos experimentos realizados pela equipe de pesquisadores da Embrapa Amazônia Oriental, nas últimas décadas, em áreas de produtores e em estações experimentais, envolvendo as culturas componentes do modelo, em sistemas de policultivo, especialmente da região do município de Tomé Açu. Os SAF experimentais em áreas de produtores que se caracterizaram, também, como unidades de observação para a equipe da Embrapa, tendo em vista a participação dos pesquisadores na definição e acompanhamento de várias dessas iniciativas de produtores. As produtividades de cupuaçu e taperebá, em fases finais de ciclo produtivo foram estimadas pelos produtores e pesquisadores, com maiores experiências no modelo de SAF e nessas culturas. De forma complementar, foi realizado um painel técnico com a participação desses pesquisadores e produtores para checagem e consolidação do modelo de SAF avaliado. O painel técnico consiste em reunir um grupo de informantes-chave (produtores e técnicos com grande conhecimento sobre um determinado tema, no caso, o cultivo de SAF ou de seus componentes, na região), visando caracterizar ou avaliar detalhadamente o sistema produtivo, sob as óticas agronômica e econômica, assim como, realizar a contextualização no ambiente socioeconômico, envolvendo a família, a propriedade, a comunidade, a cadeia produtiva e o mercado (Guiducci, Lima Filho e Mota, 2012).

Dessa forma, o modelo de SAF avaliado representa um estudo de caso de um sistema produtivo composto de cultivos agrícolas de ciclo longo, ciclo médio e ciclo curto, implantados no mesmo período, de forma consorciada em uma mesma área. As culturas de ciclo longo são representadas pelas fruteiras nativas, cupuaçuzeiro e taperebazeiro. As de ciclo médio, por pimenteira do reino e bananeira. Arroz é a espécie de ciclo curto, como parte do sistema, tendo o plantio de feijão guandu utilizada apenas para adubação verde da área.

O módulo de um hectare foi considerado na avaliação, com todas as culturas sendo implantadas no início do ano 1 do investimento, o que coincide com o princípio do período chuvoso. O preparo de área é programado para ocorrer no final do ano anterior ao de plantio, consistindo de remoção mecânica da vegetação secundária espontânea (capoeira de cerca de 4 anos), queima da vegetação removida e, aplicação e incorporação de calcário no solo.

Cupuaçuzeiro e pimenteira do reino, por serem consideradas as culturas principais do sistema, utilizam espaçamento e densidade próximos aos convencionais de monocultivo, com redução na densidade. No SAF, o espaçamento é de $6 \times 4 \mathrm{~m}$ para o cupuaçuzeiro e $2 \mathrm{x}$ $2 \times 4 \mathrm{~m}$ para a pimenteira do reino. A implantação das culturas na mesma área, no entanto, resulta em certo grau de competição por espaço, água, nutrientes e luminosidade entre si, crescente a partir do segundo ano, além da competição com as demais espécies do sistema. A bananeira é plantada com intuito de fornecer sombra provisória ao cupuaçuzeiro, enquanto o taperebazeiro é estabelecido visando o sombreamento permanente. No entanto, estas plantas não deixam de competir pelos elementos essenciais à produção, havendo, portanto, a necessidade da diminuição da densidade de plantio. Logo, a bananeira é implantada em $6 \times 4$ m e o taperebazeiro, em $30 \times 20 \mathrm{~m}$. O arroz e o guandu ocupam uma pequena porção da área de cultivo, pois têm o papel de aproveitar as entrelinhas 
dos cultivos de maior ciclo, quando estas ainda não estavam exploradas pelos mesmos, por estarem em fase inicial de crescimento e de efetiva ocupação da área. A Figura 1 apresenta um croqui que demonstra o arranjo das culturas componentes na estrutura do SAF. A Tabela 1 apresenta a densidade de plantio e as áreas efetivamente ocupadas pelas culturas componentes do sistema. Observa-se que o somatório de área efetivamente ocupada pelas culturas componentes $(2,71 \mathrm{ha})$ é maior que a área total de 1 ha, o que pressupõe o aproveitamento de entrelinhas e a competição entre espécies, resultando em redução do potencial produtivo individual, mas com ganho de produtividade, produção e receita bruta no sistema consorciado, tendo como referência os modelos de monocultivos tradicionais. A Tabela 1 apresenta, ainda, o período de ocupação de área do sistema por cada cultura componente, ao longo do período de investimento.

\section{Modelos teórico e analítico}

$\mathrm{Na}$ avaliação econômicofinanceira do sistema, foi utilizado o método da Análise de Custo Benefício (ACB) para avaliação econômicofinanceira do sistema produtivo. Para Mishan (1975), a base lógica dos estudos vigentes de custo-benefício é uma melhoria potencial de Pareto, com as duas se baseando no critério de melhor eficiência alocativa de recursos. Assim, tanto os princípios da eficiência econômica como da análise de custos-benefícios inspiram-se na melhoria potencial de Pareto, e qualquer critério que exija que os benefícios sociais excedam em valor todos os custos implica a realização de uma melhoria desse potencial. Ray (1984) considera que a ACB serve de base para avaliação econômica de projetos públicos ou privados, tendo em vista que os princípios em si são semelhantes por se basearem na alocação eficiente de recursos, ao se comparar os resultados ou benefícios líquidos de um ou diversos projetos alternativos. AACB foi utilizada nessa avaliação, com auxílio das estruturas de custos e de benefícios construídas, de acordo com a técnica de orçamento de capital. Na estruturação dos custos, foram considerados todos os serviços e materiais necessários à implantação e manutenção da área do SAF, considerando todos os seus componentes culturais, e os processos de colheita dos produtos, beneficiamento primário e transporte externo para comercialização, quando pertinentes, além dos custos de oportunidade (juro real sobre capital próprio ou de terceiros) dos recursos financeiros imobilizados em serviços, materiais e terra.

$\mathrm{Na}$ avaliação foi utilizada a abordagem de longo prazo, ou seja, como estrutura de investimento, tendo sido estimados os indicadores de viabilidade econômica, para um horizonte temporal de 30 anos,

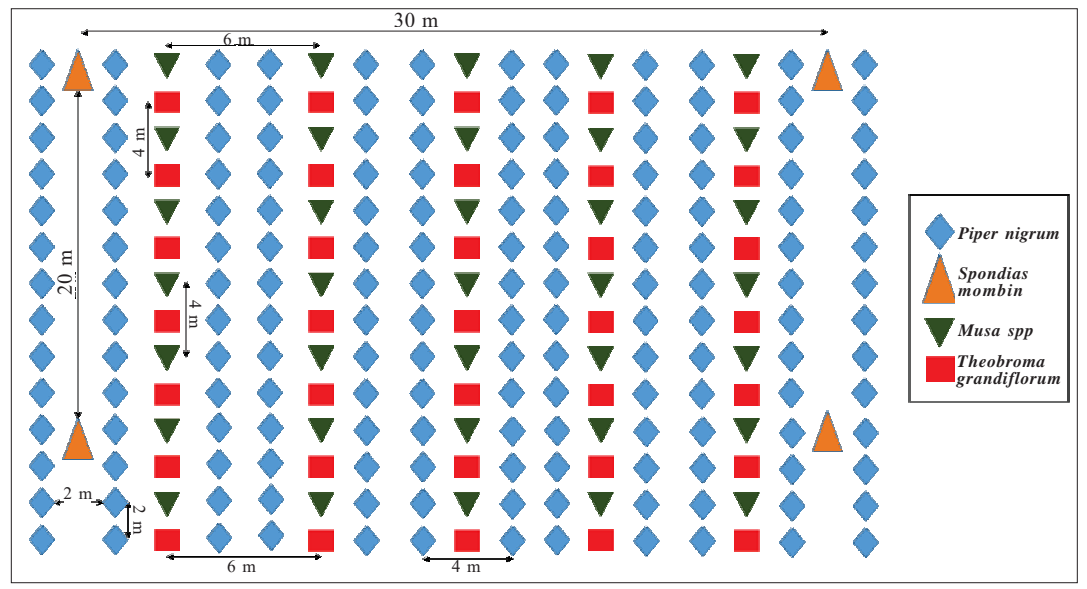

Figura 1. Croqui do stand inicial do modelo de sistema agroflorestal: Pimenteira do reino (Piper nigrum) - 2 × 2 × 4 m; Taperebazeiro (Spondias mombin) - $30 \times 20 \mathrm{~m}$; Bananeira (Musa spp) - 6 × 4 m; Cupuaçuzeiro (Theobroma grandiflorum) - 6 × 4 m; Arroz e feijão guandu nas entrelinhas, no primeiro ano de cultivo.

Tabela 1. Densidade de plantio, área efetivamente ocupada e período de ocupação da área no sistema das culturas componentes do SAF (módulo de 1 ha)

\begin{tabular}{lccc}
\hline Cultura & $\begin{array}{c}\text { Número de plantas/ } \\
\text { ha }\end{array}$ & $\begin{array}{c}\text { Área útil } \\
\text { (ha)* }\end{array}$ & $\begin{array}{c}\text { Períodos no } \\
\text { SAF (ano) }\end{array}$ \\
\hline Arroz & - & 0,29 & 0 a 1 \\
Feijão guandu & - & 0,29 & 0 a 1 \\
Banana & $375^{* *}$ & 0,34 & 0 a 5 \\
Pimenta do reino & $1.836^{* * *}$ & 0,73 & 0 a 7 \\
Cupuaçu & 375 & 0,94 & 0 a 30 \\
Taperebá & 15 & 0,12 & 0 a 30 \\
\hline
\end{tabular}

* Comparativamente a 1 ha de área com monocultivo, em arranjo convencional.

** Arranjo inicial mantido até o $5^{\circ}$ ano, mas com controle de pseudocaules nas touceiras. *** Stand inicial. Mas vai reduzindo a partir do ano 3, devido a morte de plantas por fusariose. 
que consideram o ciclo produtivo do sistema e os limites temporais necessários para análise, conforme Gittinger (1982), que estabelece um período em torno de 25 anos, como suficiente, quando o ciclo produtivo é acima disso, tendo em vista o efeito da taxa de desconto no cálculo dos indicadores. Foram utilizados os seguintes indicadores de viabilidade econômica, para avaliação do SAF completo: valor presente líquido (VPL), relação benefício-custo (RBC), taxa interna de retorno (TIR) e período de recuperação de capital ou payback econômico (PBE). O indicador custo unitário de produção (CUP) foi utilizado na avaliação do desempenho econômico das culturas agrícolas, como componentes culturais do SAF, assim como a RBC. Para isso, as despesas comuns entre dois ou mais componentes, a cada ano, foram rateadas entre eles, com base na proporção de receita financeira gerada no sistema (Hoffmann et al., 1987, Santos, 1996) e, em seguida, foram agregadas as despesas específicas, resultando no custo total. A razão entre o custo total e o volume de produção total, ambos descontados à taxa de desconto considerada na avaliação, definiu o CUP de cada cultura. Na apropriação dos custos relativos a ativos fixos e semifixos utilizados nos sistemas produtivos, levou-se em conta que esses recursos materiais se exaurem em mais de uma unidade de tempo considerada (ano) e como são, em geral, de uso compartilhado com outras atividades produtivas ou de lazer pelas famílias produtoras, essa apropriação foi realizada por meio do cálculo de equivalente-aluguel, onde são consideradas as depreciações, as despesas com manutenção e a proporção de uso em relação às demais atividades.

$\mathrm{Na}$ estrutura de custos, foram apropriadas as despesas com insumos materiais (agroquímicos, ferramentas, utensílios, máquinas, equipamentos e material genético), serviços prestados por terceiros, trabalho familiar e custo de capital, este através da taxa de desconto. Dessa forma, o resultado líquido estimado remunera o produtor pelos riscos assumidos com o investimento e pela sua capacidade empreendedora.

A partir da estrutura de custos e receitas, foram estabelecidos três cenários de desempenho econômico do modelo de $\mathrm{SAF}$, definidos pela variação dos preços de pimenta do reino. A avaliação de desempenho desses cenários foi uma demanda dos produtores que participaram do painel técnico de avaliação preliminar do modelo, e se justifica pela volatilidade dos preços da pimenta, como efeito das cotações no mercado internacional, e pela disponibilidade de dados (série histórica de preços), o que torna factível a avaliação. Para isso, foram utilizados preços de pimenta preta seca pagos aos produtores rurais, no período janeiro/ 1980 a julho/2018. Esses preços foram deflacionados com uso do IGP-DI (Índice Geral de Preços Disponibilidade Interna), definidos pela Fundação Getúlio Vargas, ordenados de forma crescente e divididos em três categorias (baixo, médio e alto). Foi utilizada a média aritmética de cada categoria em cada cenário. Isso não foi feito para os preços de cupuaçu e taperebá, principais geradores de receitas no sistema, por não haver disponibilidade de séries históricas de preços. O guandu foi considerado apenas no primeiro ano, com a função de adubação verde da área e, portanto, sem receita financeira.

Em relação aos preços de insumos e produtos considerados na avaliação do modelo, foram obtidos no mercado local de Tomé Açu, no ano de 2018, nas condições acessadas pelos produtores da Região. Para pimenta do reino, foram obtidas séries históricas de preços pagos aos produtores, da FGV, da CONAB e da Cooperativa Agrícola Mista de Tomé Açu (CAMTA).

Foi considerado o referencial metodológico de avaliação econômica de tecnologias e sistemas adotados pela Embrapa, reportado por Guiducci, Lima Filho e Mota (2012), onde constam vários casos de aplicação. A definição e a estrutura matemática dos indicadores são as seguintes:

a) Relação Benefício-Custo (RBC): definida como o quociente entre o valor atual do fluxo de benefícios a serem obtidos e o valor atual do fluxo de custos. A alternativa se mostra inviável caso a RBC seja menor do que um. Se expressa algebricamente como:

$$
R B C=\left\{\sum_{t=0}^{n} B_{t} /(1+\theta)^{t}\right\} /\left\{\sum_{t=0}^{n} C_{t} /(1+\theta)^{t}\right\}
$$

Sendo: $\mathrm{B}_{\mathrm{t}}=$ Benefícios ou receitas no t-ésimo ano; $\mathrm{C}_{\mathrm{t}}=$ Custos no t-ésimo ano $\theta=$ Taxa de desconto real, ao ano (decimal); $\mathrm{t}=0,1,2,3, \ldots, \mathrm{n}$ (anos). 
b) Valor Presente Líquido (VPL): é definido como a soma algébrica dos valores do fluxo líquido de caixa a ele associado, atualizados a uma adequada taxa de desconto. A alternativa será considerada viável se o VPL for positivo. Algebricamente, pode ser expresso como:

$$
V P L=\sum_{t=0}^{n} F l_{t} /(1+\theta)^{t}
$$

Sendo: $F l_{t}=$ Valor do fluxo líquido de caixa, obtido pela diferença entre benefícios $\left(B_{t}\right)$ e custos $\left(C_{t}\right)$, em cada período t; $\theta=$ Taxa de desconto real, ao ano (decimal); $\mathrm{t}=0,1,2, \ldots, \mathrm{n}$ (anos).

c) Taxa Interna de Retorno (TIR): É definida como o valor da taxa de desconto $(\theta)$ que torna o valor presente líquido igual a zero. A alternativa de investimento mostra-se inviável quando o valor da TIR for inferior ao custo de oportunidade do capital. Algebricamente, pode ser expressa por:

$$
\sum_{t=0}^{n} F l_{t} /(1+T I R)^{t}=0
$$

Sendo: $F l_{t}=$ Fluxo líquido de caixa de cada período $\mathrm{t}$, obtido por $B_{t}-C_{t} ; \mathrm{t}=0,1,2, \ldots, \mathrm{n}$ (anos). $\mathrm{TIR}=\theta$

d) Payback Econômico (PBE): determina o prazo para recuperação do capital inicial investido, em termos de períodos, neste caso, em anos, levando-se em conta o valor do dinheiro no tempo. O resultado precisa ser menor ou igual ao ciclo do investimento e quanto menor, melhor. Algebricamente, pode ser expresso como:

$$
\begin{gathered}
\text { PBE }=\mathrm{k} \text {, tal que } \\
\sum_{t=0}^{k} F l_{t} /(1+\theta)^{t} \geq 0 \quad \text { e } \sum_{t=0}^{k-1} F l_{t} /(1+\theta)^{t}<0
\end{gathered}
$$

Sendo: $F l_{t}=$ Fluxo líquido de caixa de cada período t, obtido por $B_{t}-C_{t}$, que são, respectivamente, benefícios e custos; $\theta=$ Taxa de desconto real, ao ano (decimal); $\mathrm{t}=0,1,2, \ldots, \mathrm{n}$ (anos). e) Custo Unitário de Produção (CUP): Definido como o custo de uma unidade produto, na avaliação das atividades (culturas) componentes do SAF. Os valores de referência foram os preços de mercado de cada produto. A CUP de cada produto deve ser inferior ou igual ao respectivo preço. Pode ser expressa, algebricamente, como:

$$
\begin{array}{r}
\operatorname{CUP}_{\mathrm{i}}=\mathrm{CTA}_{\mathrm{i}} / \mathrm{PA}_{\mathrm{i}} \\
\text { onde: } \quad C T A_{i}=\sum_{t=0}^{n} C_{i t} /(1+\theta)^{t} \\
\text { e } \mathrm{PA}_{\mathrm{i}}=\sum_{t=0}^{n} P_{i t} /(1+\theta)^{t}
\end{array}
$$

Sendo: CUP $_{\mathrm{i}}=$ Custo unitário de produção da iésima atividade; $\mathrm{CTA}_{\mathrm{i}}=$ Custo total atualizado da iésima atividade.

O custo de oportunidade de capital considerado foi de $4 \%$ ao ano, como taxa de juros, em termos reais, utilizada como taxa de desconto no cálculo dos indicadores, quando pertinente. Esse valor reflete a taxa de juros reais do crédito agrícola para pequenos produtores, disponibilizadas por meio do Fundo Constitucional do Financiamento do Norte.

Os resultados da avaliação são apresentados em duas partes. A primeira, analisa o sistema agroflorestal completo, através do desempenho dos indicadores econômicos. A segunda, analisa o desempenho de cada uma das culturas que compõem o sistema. Os cenários alternativos foram avaliados para o sistema agroflorestal e para a componente pimenta do reino.

\section{Resultados e Discussão}

Observando de maneira conjunta os indicadores, na Tabela 2, verifica-se que o modelo de sistema agroflorestal apresenta viabilidade econômica com considerável margem de segurança, considerando-se os pressupostos estabelecidos para o mesmo, tendo em vista que os indicadores calculados se mostram bem acima dos valores de referência. $\mathrm{O}$ indicador de rentabilidade TIR, que representa o retorno médio anual ao capital investido, teve valor de $23,4 \%$; situou-se 5,8 vezes acima do seu valor de referência, que representa o custo de oportunidade do capital investido. A RBC, uma medida de relação da dimensão das receitas 
Tabela 2. Indicadores de viabilidade econômico-financeira para o sistema agroflorestal (1 ha), na microrregião de Tomé Açu, Pará. 2018

\begin{tabular}{lccc}
\hline $\begin{array}{c}\text { Indicador de } \\
\text { viabilidade }\end{array}$ & Unidade & $\begin{array}{c}\text { Valor } \\
\text { Indicador }\end{array}$ & $\begin{array}{c}\text { Valor } \\
\text { Referência }\end{array}$ \\
\hline Taxa Interna de Retorno & $\%$ & 23,4 & 4,00 \\
Relação Benefício-Custo & - & 1,60 & 1,00 \\
Valor Presente Líquido & R\$ & $129.516,27$ & 0,00 \\
Prazo de Retorno do Investimento & Ano & 4 & - \\
\hline
\end{tabular}

que sejam aplicadas taxas de juros reais de até $4 \%$ ao ano ou mesmo, um pouco acima disso, havendo, também, necessidade de realização de estudos sobre mercado, quantificando demandas e comportamento de preços, em resposta a variações de oferta, resultantes de estímulo pelo comparativamente aos custos, apresentou valor que indica que para cada $\mathrm{R} \$ 1.000,00$ investido pelo agricultor no sistema, espera-se um retorno de R $\$$ 1.600,00. O VPL, medida residual que também compara receitas e custos ao longo de todo o ciclo de avaliação, apresentou valor positivo e muito acima de sua referência. $\mathrm{O}$ valor estimado para ao período de retorno de investimento, ou payback econômico, foi de 4 anos e por este valor estar dentro do período de vigência do investimento, caracteriza haver recuperação do capital investido. Em Souza et al. (2007), avaliando Sistema com eucalipto consorciado com arroz, soja e pastagem sequenciais, houve saldo negativo nos três primeiros anos, havendo saldo positivo somente a partir do quarto ano. O comportamento repetiu-se em um dos sistemas agroflorestais estudados por Sanguino et al. (2007), que avaliaram o desempenho econômico de dois SAF, envolvendo as culturas cupuaçu, pimenta do reino, maracujá e mogno amazônico (SAF-A) e açaí, cacau e mogno (SAF-B). Esse payback é considerado baixo, o que é interessante, tendo em vista se tratar de um sistema produtivo de longo prazo, onde os principais componentes são culturas perenes, e sua vida útil poderá se estender por mais de três décadas. Esse rápido retorno do investimento teve a considerável contribuição de culturas de ciclo mais rápido, como foi o caso da pimenta e da banana, que apresentaram desempenho econômico positivo. No entanto, o componente arroz apresentou desempenho negativo, influenciando de forma oposta no comportamento desse indicador e nos demais. Esse efeito financeiro negativo da cultura do arroz representou pouca relevância ao sistema, devido a pequena área ocupada pela cultura e, apenas no primeiro ano de cultivo.

Os resultados confirmam a viabilidade econômica do empreendimento, podendo ser objeto de financiamento por parte de instituições que atuam no crédito agrícola, com baixo período de carência, desde crédito, especialmente para produtos de consumo predominantemente regional, como é o caso do cupuaçu e do taperebá.

A análise a seguir avaliou o desempenho individual das atividades que compõem o modelo em questão. Consideraram-se os custos específicos de cada cultura e os custos comuns a duas ou mais culturas, que foram rateados entre os respectivos componentes do sistema, conforme a metodologia descrita.

Apesar do bom desempenho econômico do sistema completo, pode-se verificar na Tabela 3, que a cultura do arroz apresentou desempenho negativo, com a RBC abaixo de 1,00 e o custo de se produzir um $\mathrm{kg}$ de arroz ficando bem acima do preço de venda do produto. $\mathrm{O}$ mesmo comportamento do cultivo de arroz pôde ser constatado em Santos (1996) e em Souza et al. (2007). No entanto, essa performance negativa foi mais que compensada pelos demais componentes, que apresentaram rentabilidades positivas. Com isso, infere-se que o processo tecnológico de produção de arroz deve ser alterado visando a melhoria do seu desempenho econômico ou se proceda a substituição desse componente cultural por outro que cumpra a função de aproveitamento das entrelinhas ociosas, e apresente rentabilidade, contribuindo positivamente para a performance do SAF. É possível que a escala de produção da cultura tenha contribuído para o desempenho negativo, tendo em vista que apenas $29 \%$ da área foi ocupada pela mesma. O fato da cultura do arroz ser cultivada apenas no primeiro ano de implantação do SAF resultou, não só na baixa participação na geração e receita para o sistema, mas também, na baixa participação no seu custo total, o que facilita a compensação de sua performance econômica negativa, pelos demais componentes culturais de desempenho positivo e de maior participação nas receitas e despesas do sistema.

O componente cultural banana apresentou viabilidade econômica, com uma RBC bem acima de 
Tabela 3 - Indicadores de Desempenho Econômico dos Componentes Culturais do Sistema Agroflorestal. Tomé Açu, Pará. 2018

\begin{tabular}{l|rr|rr|r|rr}
\hline \multirow{2}{*}{ Cultura } & \multicolumn{2}{|c|}{ Receita $^{-}$Total $^{1}$} & \multicolumn{2}{|c|}{ Custo Total $^{1}$} & RBC $^{2}$ & \multicolumn{2}{c}{ CUP $^{3}$} \\
\cline { 2 - 8 } & $\mathbf{( R \$ )}$ & $\mathbf{\%}$ & $\mathbf{( R \$ )}$ & $\mathbf{\%}$ & - & Unid. & Valor \\
\hline Arroz & 384,6 & 0,1 & 692,6 & 0,3 & 0,56 & $\mathrm{R} \$ / \mathrm{kg}$ & 1,80 \\
Banana & $14.954,3$ & 4,3 & $7.945,1$ & 3,7 & 1,88 & $\mathrm{R} \$ /$ cacho & 2,66 \\
Pimenta do reino & $94.761,8$ & 27,4 & $83.795,0$ & 38,8 & 1,13 & $\mathrm{R} \$ / \mathrm{kg}$ & 6,46 \\
Cupuaçu & $142.338,7$ & 41,3 & $71.710,3$ & 33,2 & 1,98 & $\mathrm{R} \$ / \mathrm{kg}$ & 0,50 \\
Taperebá & $92.968,8$ & 26,9 & $51.748,9$ & 24,0 & 1,80 & $\mathrm{R} \$ / \mathrm{kg}$ & 0,56 \\
\hline SAF (Total) & $\mathbf{3 4 5 . 4 0 8 , 2}$ & $\mathbf{1 0 0 , 0}$ & $\mathbf{2 1 5 . 8 9 1 , 9}$ & $\mathbf{1 0 0 , 0}$ & $\mathbf{1 , 6 0}$ & - & - \\
\hline
\end{tabular}

Valores de referência (preços de venda): Arroz em casca $(\mathrm{R} \$ 1,00 / \mathrm{kg})$; Banana (R\$ $\mathrm{R} \$ 5,00 /$ cacho); pimenta do reino preta e seca $(\mathrm{R} \$ 7,30 / \mathrm{kg})$; Cupuaçu ( $\mathrm{R} \$ 1,00 / \mathrm{kg}$ fruto) e taperebá ( $\mathrm{R} \$ 1,00 / \mathrm{kg}$ fruto).

${ }^{1}$ Somatório de todo o ciclo de análise do SAF. Valor descontado, a taxa de desconto de $4 \%$ a.a. ${ }^{2}$ Relação benefício-custo, no horizonte de 30 anos (período de análise do SAF).

${ }^{3}$ Custo unitário de produção.

1,00 e o custo de produção de um cacho da fruta consideravelmente abaixo do preço comercial e de referência $(\mathrm{R} \$ 2,66$ e $\mathrm{R} \$ 5,00)$. A rentabilidade positiva contribuiu favoravelmente para a performance econômica do SAF. A cultura apresentou participação relativamente baixa na geração de receitas pelo $\mathrm{SAF}$, mas apresentou resultado semelhante em termos de participação nos custos totais do sistema, devido a permanecer apenas em 6 dos 30 anos do ciclo de avaliação do sistema (Tabelas 3 e 1).

Com relação aos três principais componentes culturais do SAF, verifica-se que todos apresentaram rentabilidade, contribuído positivamente para a viabilidade econômica do sistema. Todos apresentaram RBC bem acima de 1,00 e o custo de produção de uma unidade física de produto abaixo do preço de mercado e de referência. No caso da pimenta do reino ( $\mathrm{R} \$ 6,46$ e $\mathrm{R} \$ 7,30)$, do cupuaçu ( $\mathrm{R} \$ 0,50$ e $\mathrm{R} \$ 1,00)$ e do taperebá $(\mathrm{R} \$ 0,56$ e $\mathrm{R} \$ 1,00)$. A cultura da pimenta, apesar de permanecer em apenas 8 dos 30 anos do sistema (Tabela 1), foi responsável pela segunda maior participação nas receitas e pela maior participação nos custos totais do SAF. Isto se deve ao preço comercial do produto pimenta ser bem maior em relação aos frutos do cupuaçu e taperebá, na composição das receitas e, pelo lado das despesas, necessitar de elevados valores de investimento em estacas para tutoramento das plantas e intensivo uso de adubos no processo produtivo. Sanguino et al. (2007), ao avaliarem dois sistemas agroflorestais, sendo um deles sem a cultura da pimenta-do-reino, atestou que este apresentou os dois primeiros anos deficitários, e atribuiu este prejuízo à ausência da cultura. As culturas cupuaçu e taperebá permanecem no sistema durante todo o ciclo de análise, iniciando suas fases produtivas a partir dos anos 3 e 4 , respectivamente, o que concorre para suas elevadas participações nas receitas e nos custos gerados pelo sistema. As altas produtividades esperadas para essas duas culturas também concorrem para a geração das elevadas receitas. Cupuaçu apresenta as maiores participações na composição das receitas do SAF e a segunda maior participação nos custos, ficando atrás apenas da pimenta do reino. Taperebá apresenta as menores participações de receitas e custos, considerando-se os três principais componentes do sistema, tendo a justificativa de ter baixa densidade de plantas (apenas 15 plantas no módulo de 1 hectare), comparativamente aos demais componentes culturais considerados principais. Segundo Cordeiro (2010), o espaçamento pode ser responsável por resultados negativos ou positivos nos fluxos de caixa de investimento.

A Tabela 4 apresenta os indicadores de viabilidade e de desempenho econômico-financeiro para o sistema agroflorestal completo e para a componente pimenta do reino, quando se considera o cenário de preços baixos de pimenta. O preço utilizado na avaliação foi de $\mathrm{R} \$ 6,20 / \mathrm{kg}$ de pimenta preta seca, estimado como média do primeiro tercil da série histórica de preços mensais pagos aos produtores no período 1980-2018, ordenados de forma crescente. Considerando que o preço de pimenta nesse cenário representa o preço médio de período de baixa cotação, e que esse preço é inferior à média dos preços pagos aos produtores em 2018 ( $\mathrm{R} \$ 7,30 / \mathrm{kg}$ de pimenta), considerado no modelo básico do sistema, os indicadores de viabilidade do SAF apresentaram desempenho inferior, com redução nos valores estimados para TIR, RBC e VPL, e um prazo maior de recuperação de capital, o que também representa uma desvantagem. No entanto, a perda de desempenho do sistema completo ocasionado pela pimenta do reino, acrescido aos do componente 
arroz, foi compensado pela performance positiva dos componentes banana, cupuaçu e taperebá, que não tiveram suas estruturas individuais básicas de receitas e despesas alterados.

Quando se analisa o desempenho da componente pimenta do reino, ainda na Tabela 4, os indicadores mostram que cultura apresentou um desempenho moderadamente negativo, com sua RBC abaixo do valor de referência e o custo unitário de produção um pouco acima do preço de referência. Para cada $\mathrm{R} \$ 1.000,00$ de despesas com o processo de produção de pimenta, o produtor tem um retorno de $\mathrm{R} \$ 970,00$, assim como uma perda de $\mathrm{R} \$ 0,19$ para cada $\mathrm{kg}$ de pimenta vendida, considerando os pressupostos do modelo e o preço médio das cotações mais baixas do produto.

Quando se considera o preço representativo do segundo tercil da série, ou seja, os preços de nível intermediário pago ao produtor (no caso, $\mathrm{R} \$ 11,30 / \mathrm{kg}$ de pimenta), o modelo de sistema agroflorestal apresenta uma forte elevação no desempenho econômico-financeiro, conforme pode-se verificar na Tabela 5, com indicadores TIR, RBC e VPL muito acima dos valores de referência e bem mais elevados em relação aos indicadores obtidos para o modelo básico, que considera os preços médios de pimenta para o ano de 2018, quando o estudo foi realizado. O

Tabela 4. Indicadores de viabilidade e desempenho econômico-financeiro para o sistema agroflorestal e a componente pimenta do reino (1 ha), para o cenário de preços baixos de pimenta, na microrregião de Tomé Açu, Pará. 2018

\begin{tabular}{lcccc}
\hline \multicolumn{1}{c}{ Indicador } & Unid. & SAF & Pimenta & V. Referência \\
\hline Taxa Interna de Retorno & $\%$ & 19,7 & - & 4,00 \\
Relação Benefício-Custo & - & 1,53 & 0,97 & 1,00 \\
Valor Presente Líquido & $\mathrm{R} \$$ & $115.237,09$ & - & 0,00 \\
Prazo de Retorno do Investimento & Ano & 5 & - & - \\
Custo Unitário de Produção & $\mathrm{R} \$ \mathrm{~kg}$ & - & 6,39 & 6,20 \\
\hline
\end{tabular}

Tabela 5. Indicadores de viabilidade e desempenho econômico-financeiro para o sistema agroflorestal e a componente pimenta do reino (1 ha), para o cenário de preços medianos de pimenta, na microrregião de Tomé Açu, Pará. 2018

\begin{tabular}{lcccc}
\hline \multicolumn{1}{c}{ Indicador } & Unid. & SAF & Pimenta & V. Referência \\
\hline Taxa Interna de Retorno & $\%$ & 38,4 & - & 4,00 \\
Relação Benefício-Custo & - & 1,84 & 1,70 & 1,00 \\
Valor Presente Líquido & $\mathrm{R} \$$ & $180.921,29$ & - & 0,00 \\
Prazo de Retorno do Investimento & Ano & 3 & - & - \\
Custo Unitário de Produção & $\mathrm{R} \$ \mathrm{~kg}$ & - & 6,64 & 11,30 \\
\hline
\end{tabular}

prazo de recuperação de capital reduziu de quatro para três anos. Na avaliação da componente pimenta, o desempenho econômico também apresenta uma elevação positiva considerável, com a RBC saindo de 1,60 , no modelo básico, para 1,70, quando se considera o preço mediano de pimenta. O custo de produção de um $\mathrm{kg}$ de pimenta $(\mathrm{R} \$ 6,64)$ focou bem abaixo do preço de venda do produto ( $\mathrm{R} \$ 11,30 / \mathrm{kg})$.

Optou-se por não apresentar os resultados para o cenário que consideraria o preço de pimenta pago ao produtor, como representativo do tercil superior da série histórica de preços, ou seja, preço para período de elevada cotação da pimenta, tendo em vista que em termos qualitativos esses resultados seriam semelhantes ao do cenário com preços medianos, diferindo apenas nos valores quantitativos dos indicadores, que apresentariam uma robusta elevação.

\section{Conclusões}

Os resultados obtidos demonstram que o modelo de sistema agroflorestal avaliado apresenta viabilidade econômico-financeira com boa margem de segurança, considerando os pressupostos definidos, o que o caracteriza como uma boa opção de investimento por parte dos agricultores da região. Os componentes culturais bananeira, cupuaçuzeiro, pimenteira do reino e taperebazeiro também apresentaram desempenho econômico positivo no sistema, colaborando para a viabilidade do SAF. No entanto, o componente arroz apresentou desempenho econômico negativo, o que indica que deve passar por ajustes no seu processo produtivo, tecnológico ou de gestão, que promova melhoria significativa no desempenho, ou mesmo ser substituído por outro componente agrícola, que desempenhe a função de aproveitamento das entrelinhas das culturas de ciclo mais longo, e que apresente resultado econômico positivo.

Para o cenário de baixo preço de pimenta, essa componente 
apresentou desempenho econômico-financeiro negativo, mas de baixa intensidade. Isso culminou para redução da rentabilidade do sistema agroflorestal que, ainda assim, apresentou-se viável economicamente e em nível considerável, como efeito da boa performance dos componentes banana, cupuaçu e taperebá.

\section{Agradecimentos}

Os autores agradecem a eng. agrônoma Claudeli M Arnand (da Fazenda Konagano), pela importante participação na obtenção e revisão dos dados agronômicos do sistema; ao pesquisador da Embrapa, Adilson da Silva Elleres, pelos dados de preços e revisão bibliográfica; aos técnicos ou produtores Michinori Konagano, Elton Takaki, Emerson Y. Shioya, Roberto Hanawa e Ivan H. Saiki (da Cooperativa Agrícola Mista de Tomé-açu - CAMTA); a Jasson L. P. Moreira (da Comissão Executiva do Plano da Lavoura Cacaueira CEPLAC); a Cícero S. Silva (da Secretaria Municipal de Agricultura de Tomé Açu) e a Felício H. Inada (do Banco da Amazônia), pela checagem dos dados e validação do modelo e da análise.

\section{Literatura Citada}

ALVES, R. M. et al. 2018. Spondias mombin and Theobroma grandiflorum in agroforestry system: productivity implications. Revista Brasileira de Fruticultura 40(6):e-061.

ARAÚJO, A. C. et al. 2015. Análise financeira do sistema agroflorestal cacaueiro com seringueira na mesorregião sul baiano. Agrotrópica (Brasil) 27(1):15-18.

ARMENGOT, L. et al. 2016. Cacao agroforestry systems have higher return on labor compared to full-sun monocultures. Agronomy for Sustainable Development, Springer Verlag/EDP Sciences/ INRA, 36(4). 10p.

BARROS, A. V. L. de, et al. 2009. Evolução e percepção dos sistemas agroflorestais desenvolvidos pelos agricultores nipo-brasileiros do município de Tomé Açu, estado do Pará. Amazônia: Ciência \& Desenvolvimento (Brasil) 5(9):121-151.

BOLFE, E. L.; BATISTELLA, M. 2011. Análise florística e estrutural de sistemas silviagrícolas em ToméAçu, Pará. Pesquisa Agropecuária Brasileira 46(10):1139-1147.
CERDA, R. et al. 2014. Contribution of cocoa agroforestry systems to family income and domestic consumption: looking toward intensification. Agroforestry systems 88(6):957-981.

CORDEIRO, S. A. 2010. Avaliação econômica e simulação em sistemas agroflorestais. Tese Doutorado. Viçosa, MG, UFV. 96p.

GITTINGER, J. P. 1982. Economic Analysis of agricultural projects. Washington, D.C, EDI/World Bank. 505p.

GUIDUCCI, R. C. N.; LIMA FILHO, J. R.; MOTA, M. M. 2012. Viabilidade econômica de sistemas de produção agropecuários: metodologia e estudos de caso. Brasília, DF, Embrapa. 535p.

HENKEL, K.; AMARAL, I. G. 2008. Análise agrossocial da percepção de agricultores familiares sobre sistemas agroflorestais no nordeste do estado do Pará, Brasil. Boletim do Museu Paraense Emílio Goeldi. Ciências Humanas (Brasil) 3(3):311-327.

HOFFMANN, R. et al. 1987. Administração da empresa agrícola. São Paulo, SP, Pioneira. 325p.

PALUDO, R.; COSTABEBER, J. A. 2012. Sistemas agroflorestais como estratégia de desenvolvimento rural em diferentes biomas brasileiros. Revista Brasileira de Agroecologia 7(2):63-76.

MISHAN, E. J. 1975. Elementos de análises de custosbenefícios. Rio de Janeiro: Zahar Editores. 202p.

RAY, A. 1984. Cost-Benefit Analysis: Issues and Methodologies. Washington, World Bank. 159p.

SANGUINO, A. C. et al. 2007. Avaliação econômica de sistemas agroflorestais no estado do Pará. Revista de Ciências Agrárias (Brasil) 47:71-88.

SANTOS, J. C. 1996. Análise da rentabilidade, sob condições de risco, de um sistema agroflorestal adotado por pequenos produtores de cacau na região da Transamazônica, Pará. Dissertação Mestrado. Fortaleza, CE, UFC. 127p.

SILVA, D. P. 2013. SAF: sistemas alternativos de produção. Revista de Extensão e Estudos Rurais (Brasil) 2(1):153-162.

SOUZA, A. N. de, et al. 2007. Viabilidade econômica de um sistema agroflorestal. Cerne 13(1):96-106.

VARELA, L. B.; SANTANA, A. C. de, 2009. Aspectos econômicos da produção e do risco nos sistemas agroflorestais e nos sistemas tradicionais de produção agrícola em Tomé Açu, Pará - 2001 a 2003. Revista Árvore (Brasil) 33(1):151-160. 